
\title{
$\angle S$ Research Square \\ Factors Related to Hypocalcemia in human Brucellosis: a retrospective review
}

\section{Qing Zhen (D 1010609845@qq.com )}

Jilin University School of Public Health

Xiaohan Zhang

Jilin University School of Public Health

\section{Siwen Zhang}

Jilin University School of Public Health

\section{Qianqian Chen}

Jilin University School of Public Health

Xiangyi Zhang

Jilin University School of Public Health

\section{Huixin Yang}

Jilin University School of Public Health

\section{Taijun Wang}

Jilin University School of Public Health

\section{Fangfang Hu}

Jilin University School of Public Health

Jingjing Luo

Jilin University School of Public Health

Jing Hu

Jilin University School of Public Health

\section{Peng Zhang}

Jilin University School of Public Health

\section{Research article}

Keywords: Human brucellosis;Hypocalcemia;Retrospective review

Posted Date: February 20th, 2020

DOI: https://doi.org/10.21203/rs.2.24027/v1

License: (c) (i) This work is licensed under a Creative Commons Attribution 4.0 International License. Read Full License 


\section{Abstract}

Background. In recent years, some severe complications of brucellosis have been raised many researchers'concern. Hypocalcemia, which is commonly seen in serious infectious diseases, such as sepsis, severe bacterial pneumonia and AIDS, has been reported less in Brucellosis. To our knowledge, serious consequences would be caused by hypocalcemia. Some studies have provided evidence of high serum calcium levels in patients with brucellosis, but few studies have reported the incidence and impact of brucellosis hypocalcemia,except for one case of rifampic-associated hypocalcemia. Objective . To summarize the clinical and epidemiological characteristics, to explore the influence of hypocalcemia on brucellosis.In addition, the purpose of this study was to investigate the relationship between rifampicin in the treatment of brucellosis and secondary hypocalcemia, so as to provide clinical guidance. Methods. A retrospective study was carried out to review the records of 572 brucellosis patients from January 2015 to December 2016 of a hospital in shenyang, liaoning province, China.Patients were divided into three groups according to the serum calcium level, one group of 102 patients was hypocalcemia ,one group of 442 patients was normal corrected calcium and the other group of 28 patients was hypercalcemia. Results . The history of administration of rifampicin $\nabla \mathrm{OR}=2.098$, $95 \% \mathrm{Cl}=1.145 \sim 3.844$ and tetracycline $\otimes \mathrm{OR}=2.105,95 \% \mathrm{Cl}=1.266 \sim 3.501$ are the related factors of hypocalcemia. Conclusions. Further evaluation in randomized clinical trials of the indicative role of hypocalcimia is needed to be followed up.Provide evidence for the risk factors of hypocalcemia in brucellosis patients with the history of rifampicin administration.

\section{Introduction}

Brucellosis is a common infectious disease affecting both humans and animals. The disease usually cause fever, fatigue, sweating, arthritis, and enlargement of the liver and spleen ${ }^{[1]}$. Nevertheless, the disease has a wide range of clinical manifestations including musculoskeletal, digestive, urogenital, hematological, cardiovascular, respiratory, and central nervous system symptoms ${ }^{[2]}$.Brucellosis can causes a number of complications that complicate its treatment.In recent years, Brucella endocarditis, disseminated intravascular coagulation (DIC),acute hepatitis and other severe complications of brucellosis have raised many researchers concern ${ }^{[3-5]}$.It is reported that brucellosis can also cause calcium disorder, including hypercalcemia and hypocalcemia.

In recent years, many researchers have found that hypocalcemia can be caused by serious infectious diseases, such as sepsis, severe bacterial pneumonia ${ }^{[6]}$ and AIDS. Serum total calcium and Ca2 + level are reduced in sepsis patients, and they are associated with the severity of infection, the more serious the infection, the lower the blood calcium ${ }^{[7]}$.

Some researchs have provided evidence of higher serum calcium levels in patients with brucellosis ${ }^{[8-}$ ${ }^{10}$, which has described the phenomenon of the increase of serum calcium in the patients with Brucella.but few research has been reported on the incidence and influence of hypocalcemia in 
brucellosis, except one case with Rifampin-associated hypocalcemia was reported ${ }^{[11]}$.In addition, studies have shown that rifampicin is a risk factor for treating active TB in people already at risk for vitamin D deficiency, which may lead to symptomatic hypocalcemia ${ }^{[12]}$.

We collected 572 brucellosis patients from January 2015 to December 2016 of a hospital in shenyang, liaoning province, China and were aimed to summarize the clinical and epidemiology characteristics, to explore the effect of hypocalcemia on brucellosis, and to speculate the role of hypocalcemia in the pathogenesis of brucellosis. In addition, the purpose of this study was to investigate the relationship between rifampicin in the treatment of brucellosis and secondary hypocalcemia, so as to provide clinical guidance.

\section{Materials And Methods}

In our study, we retrospectively reviewed the records of 572 brucellosis patients from January 2015 to December 2016 of a hospital in shenyang, liaoning province, China.The demographic data, clinical characteristics, complications, laboratories findings and medication history of brucellosis patients were reviewed.

Since the decrease of albumin in patients had an effect on serum calcium, calcium correction formula was adopted: adjusted $[\mathrm{Ca}](\mathrm{mmol} / \mathrm{L})=$ total $[\mathrm{Ca}](\mathrm{mmol} / \mathrm{L})+0.02(40-[$ albumin $](\mathrm{g} / \mathrm{L}))$.Albumin ranges from 35 to $50 \mathrm{~g} / \mathrm{L}^{[13]}$.According to the corrected calcium level, patients were divided into three groups:

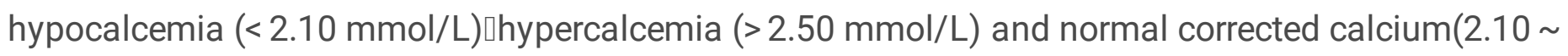
$2.50 \mathrm{mmol} / \mathrm{L}$ ). All patients were diagnosed as brucellosis on the basis of criteria established by the National Health and Family Planning Commission of China (WS 269-2007) ${ }^{[14]}$.We wanted to compare the relationship between brucellosis patients with hypocalcemia group and normal corrected calcium group, we conducted one-way ANOVA and multivariate analysis of the hypocalcemia group and normal corrected calcium group.

Data were analyzed using SPSS 24.0. For categorical variables, the chi-square test was used. When the chi-square condition was not met, Fisher's exact was used. The Wilcoxon rank-sum test was used for continuous variables that were not normally distributed. A p-value $<0.05$ was considered statistically significant. Multivariate analysis was performed using a non-conditional Logistic regression.

\section{Results}

\section{Brucellosis patient characteristics}

Findings from our study suggested that brucellosis is more common in male(71.7\%) with the sex ratio(male:female) of 2.53:1, prone to onset after 21 years of age(97.4\%),widespread in non-occupational exposure crowd(79.7\%), more contact with sheep(64.5\%),In addition, we divided the onset of the disease into three stages:Acute ( $<3$ months), Subacute(3-6 months),Chronic ( $>6$ months), brucellosis often was 
diagnosed in acute phase ( $0-3$ months)(79.2\%). $13.8 \%$ of patients had received rifampin and $15.7 \%$ of patients had been diagnosed with brucellosis before this diagnosis(Table 1).

Clinical manifestations are fever(69.6\%), fatigue(68.2\%), mental symptom(4\%), and even pleural effusion which can be life-threatening.In addition, spondylitiscan be accompanied.The positive rate of Brucella was increased by $34.9 \%$ (Table 2 ).

Table 1

Demographic and epidemiological characteristics

of patients with brucellosis $(n=572)$

\begin{tabular}{|c|c|c|}
\hline characteristics & $\mathbf{n}$ & $\%$ \\
\hline \multicolumn{3}{|l|}{ Sex } \\
\hline Male & 410 & 71.7 \\
\hline Female & 162 & 28.3 \\
\hline \multicolumn{3}{|l|}{ Age } \\
\hline $0 \sim 20$ & 15 & 2.6 \\
\hline $21 \sim 40$ & 117 & 20.5 \\
\hline $41 \sim 60$ & 347 & 60.7 \\
\hline $61 \sim 80$ & 93 & 16.3 \\
\hline \multicolumn{3}{|l|}{ Occupation } \\
\hline non-occupational exposure & 456 & 79.7 \\
\hline occupational exposure & 116 & 20.3 \\
\hline \multicolumn{3}{|l|}{ Contact history } \\
\hline Sheep & 369 & 64.5 \\
\hline Cattle & 221 & 38.6 \\
\hline \multicolumn{3}{|l|}{ Past medical history } \\
\hline Brucellosis & 90 & 15.7 \\
\hline \multicolumn{3}{|l|}{ Medication history } \\
\hline Rifampicin & 79 & 13.8 \\
\hline Tetracycline & 532 & 93.0 \\
\hline
\end{tabular}


Table 2

Clinical characteristics of patients with brucellosis $(n=572)$

\section{characteristics}

Staging

Acute ( $<3$ months)

Subacute(3-6 months)

Chronic (> 6 months)

Symptoms

Fever

Hyperhidrosis

Fatigue

Headache

Dizziness

Anorexia

Knee pain

Spinal pain

Signs

Mental symptom

Splenomegaly

Complications

Brucellosis spondylitis

Meningitis

Hyponatremia

Hypochloridemia

Hypocalcemia

Hypoproteinemia

Liver cirrhosis

Pneumonia n

453

65

54

398

240

390

93

69

28

101

322

23

13

4.0

2.3

.4
69.6

42.0

68.2

16.3

12.1

4.9

17.7

56.3

1.4

.




\begin{tabular}{|lcc|}
\hline characteristics & $\mathbf{n}$ & $\%$ \\
\hline Blood culture $(\mathrm{n}=564)$ & & \\
\hline Brucella & 197 & 34.9 \\
\hline Candida Albicans & 24 & 4.3 \\
\hline Inflammation marker & 375 & 65.6 \\
\hline CRP & 238 & 43.1 \\
\hline PCT $(n=552)$ & & \\
\hline $\begin{array}{l}\text { According to the corrected calcium level, patients were divided into three groups: 102 patients with } \\
\text { hypocalcemia } 28 \text { patients with hypercalcemia and 442 patients with normal corrected calcium. }\end{array}$ \\
\hline
\end{tabular}

\section{Univariate logistic regression analysis between hypocalcemia group and normal corrected calcium group}

we are concerned about the risk factors of hypocalcemia in brucellosis, univariate logistic regression analysis was performed in hypocalcemia group and normal corrected calcium group. According to the results,, There is a correlation between Sex $\square$ Age, Contact history of Cattle, Medication history of Rifampicin,Mental symptom, Headache,Anorexia, Knee pain and the occurrence of hypocalcemia( $\mathrm{p}<$ 0.05)(Table 3). 
Table 3

Description of patient characteristics between two groups $(n=544)$

\begin{tabular}{|c|c|c|c|c|c|}
\hline Characteristics & & Hypocalcemia & $\begin{array}{l}\text { Normal corrected } \\
\text { calcium }\end{array}$ & $x^{2}$ & $\begin{array}{l}\mathrm{P} \text { - } \\
\text { value }\end{array}$ \\
\hline \multirow[t]{3}{*}{ Sex } & & & & 10.579 & $0.001^{a}$ \\
\hline & Male & $60(58.8 \%)$ & $331(74.9 \%)$ & & \\
\hline & Female & $42(41.2 \%)$ & $111(25.1 \%)$ & & \\
\hline \multirow[t]{5}{*}{ Age } & & & & 9.399 & $0.024^{\mathrm{a}}$ \\
\hline & $0 \sim 20$ & $4(3.9 \%)$ & $11(2.5 \%)$ & & \\
\hline & $21 \sim 40$ & $25(24.5 \%)$ & $86(19.5 \%)$ & & \\
\hline & $41 \sim 60$ & $66(64.7 \%)$ & $261(59.0 \%)$ & & \\
\hline & $61 \sim 80$ & $7(6.9 \%)$ & $84(19.0 \%)$ & & \\
\hline \multirow[t]{3}{*}{ Occupation } & & & & 2.161 & 0.142 \\
\hline & $\begin{array}{l}\text { non-occupational } \\
\text { exposure }\end{array}$ & $26(25.5 \%)$ & $84(19.0 \%)$ & & \\
\hline & $\begin{array}{l}\text { occupational } \\
\text { exposure }\end{array}$ & $76(1.5 \%)$ & $358(81.0 \%)$ & & \\
\hline \multicolumn{6}{|l|}{ Contact history } \\
\hline & Sheep & $49(48.0 \%)$ & $298(67.4 \%)$ & 13.477 & $<.001$ \\
\hline & Cattle & $59(57.8 \%)$ & 154(34.8\%) & 18.405 & $<001$ \\
\hline \multicolumn{6}{|l|}{$\begin{array}{l}\text { Past medical } \\
\text { history }\end{array}$} \\
\hline & Brucellosis & $18(17.6 \%)$ & $65(14.7 \%)$ & 0.554 & 0.456 \\
\hline \multicolumn{6}{|l|}{$\begin{array}{l}\text { Medication } \\
\text { history }\end{array}$} \\
\hline & Rifampicin & $23(22.5 \%)$ & $55(12.4 \%)$ & 6.891 & $0.009^{a}$ \\
\hline & Tetracycline & $95(93.1 \%)$ & $413(93.4 \%)$ & 0.012 & 0.912 \\
\hline \multirow[t]{2}{*}{ Staging } & & & & 2.367 & 0.306 \\
\hline & Acute(<3 months) & $87(85.3 \%)$ & $347(78.5 \%)$ & & \\
\hline
\end{tabular}

Note: ${ }^{\text {a }} \mathrm{P}<0.05$ 


\section{Characteristics}

\begin{tabular}{|lllll|} 
& Hypocalcemia & $\begin{array}{l}\text { Normal corrected } \\
\text { calcium }\end{array}$ & $\chi^{2}$ & $\begin{array}{l}\text { P- } \\
\text { value }\end{array}$ \\
\hline $\begin{array}{l}\text { Subacute(3-6 } \\
\text { months) }\end{array}$ & $8(7.8 \%)$ & $51(11.5 \%)$ & \\
\hline Chronic(>6 months) & $7(6.9 \%)$ & $44(10.0 \%)$ & \\
\hline
\end{tabular}

Symptoms

\begin{tabular}{lllll} 
Fever & $58(56.9 \%)$ & $318(71.9 \%)$ & 8.833 & 0.003 \\
\hline Hyperhidrosis & $36(35.3 \%)$ & $192(43.4 \%)$ & 2.258 & 0.133 \\
\hline Fatigue & $69(67.6 \%)$ & $298(67.4 \%)$ & 0.002 & 0.965 \\
\hline Headache & $29(28.4 \%)$ & $61(13.8 \%)$ & 12.848 & $<$ \\
\hline Dizziness & $16(15.7 \%)$ & $48(10.9 \%)$ & 1.860 & 0.173 \\
\hline Anorexia & $9(8.8 \%)$ & $18(4.1 \%)$ & 3.966 & $0.046^{\mathrm{a}}$ \\
\hline Knee pain & $26(25.5 \%)$ & $74(16.7 \%)$ & 4.227 & $0.040^{\mathrm{a}}$ \\
\hline
\end{tabular}

Signs

\begin{tabular}{lllll} 
Mental symptom & $10(9.8 \%)$ & $17(3.8 \%)$ & 6.236 & $0.013^{\mathrm{a}}$ \\
\hline Splenomegaly & $4(3.9 \%)$ & $9(2.0 \%)$ & 0.584 & 0.445
\end{tabular}

Complications

\begin{tabular}{|lllll|}
$\begin{array}{l}\text { Brucellosis } \\
\text { spondylitis }\end{array}$ & $46(45.1 \%)$ & $289(65.4 \%)$ & 14.416 & $\begin{array}{c}< \\
0.001\end{array}$ \\
\hline Meningitis & $8(7.8 \%)$ & $21(4.8 \%)$ & 1.570 & 0.210 \\
\hline Hypocalcaemia & $6(5.9 \%)$ & $17(3.8 \%)$ & 0.420 & 0.517 \\
\hline Hyponatremia & $10(9.8 \%)$ & $28(6.3 \%)$ & 1.535 & 0.215 \\
\hline Hypoproteinemia & $3(2.9 \%)$ & $6(1.4 \%)$ & 0.490 & 0.484 \\
\hline Hypocalcemia & $8(7.8 \%)$ & $20(4.5 \%)$ & 1.869 & 0.172 \\
\hline
\end{tabular}

Blood culture $(\mathrm{n}=$ 536)

\begin{tabular}{|lllll|} 
Brucella & $23(22.8 \%)$ & $160(36.8 \%)$ & 7.155 & 0.007 \\
\hline Candida Albicans & $4(4.0 \%)$ & $16(3.7 \%)$ & 0.000 & 1.000
\end{tabular}




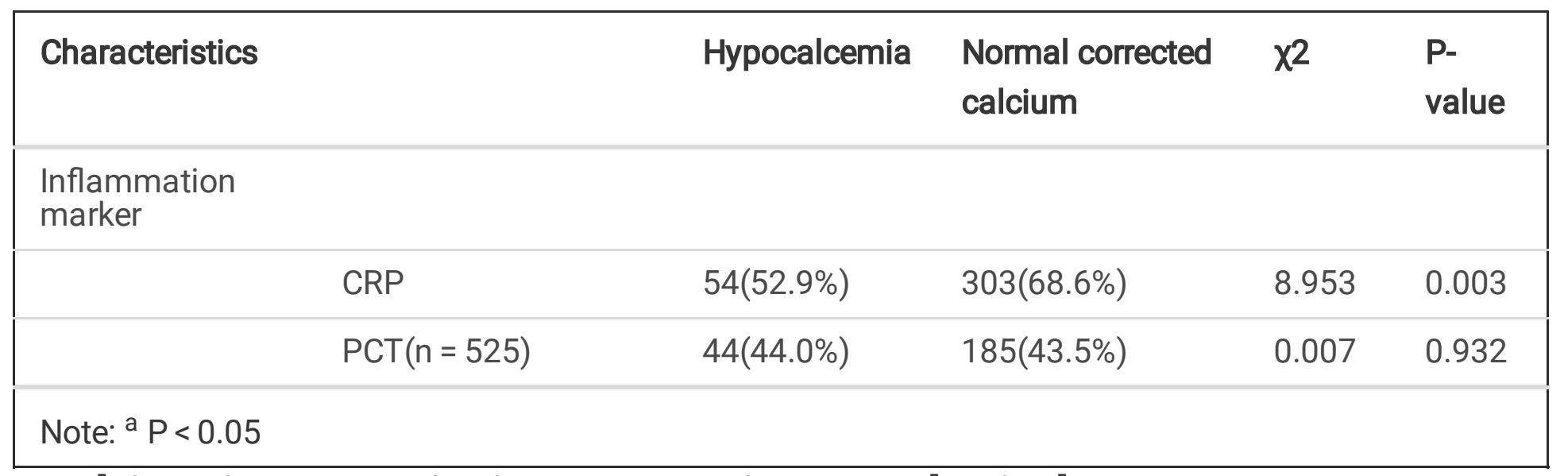

\section{Multivariate Logistic regression analysis between hypocalcemia group and normal corrected calcium group}

There may be a correlation between the above single factors, excluding confounding into independent factors: sex, age,contact history, previous history of brucella, medication history of rifampicin and tetracycline were independent variables.Logistic regression analysis, the inclusion level was 0.05 , and the exclusion standard was 0.10 . Dummy variables were set for classification variables. To explore the related factors of brucellosis combined with hypocalcemia.

Multivariate Logistic regression analysis was conducted to determine whether brucellosis patients were associated with hypocalcemia. The results showed that:the history of administration of rifampicin(OR = $1.895,95 \% \mathrm{Cl}=1.019 \sim 3.524$ ) and contact with cattle $\square \mathrm{OR}=2.242,95 \% \mathrm{Cl}=1.351 \sim 3.723 \square$ are the related factors of hypocalcemia. 
Table 4

Logistic regression analysis of brucellosis associated with hypocalcemia

\begin{tabular}{|llllllll|}
\hline Variable & & B & S.E. & WaldX2 & P value & $95 \%$ Cl & OR \\
\hline Sex & & -0.771 & 0.245 & 9.885 & 0.002 & $(0.286,0.748)$ & 0.463 \\
\hline Age & & & & & & & \\
\hline & $21 \sim 40$ & -1.204 & 0.749 & 2.585 & 0.108 & $(0.069,1.302)$ & 0.300 \\
& $41 \sim 60$ & -0.771 & 0.496 & 2.421 & 0.120 & $(0.175,1.222)$ & 0.463 \\
& $61 \sim 80$ & -0.769 & 0.444 & 3.005 & 0.083 & $(0.194,1.106)$ & 0.463 \\
\hline Cattle contact & & & & & & & \\
\hline & Cattle & 0.788 & 0.460 & 2.928 & 0.087 & $(0.892,5.422)$ & 2.199 \\
\hline Rifampicin & Sheep & 0183 & 0.459 & 0.159 & 0.690 & $(0.488,2.954)$ & 1.201 \\
\hline tetracycline & & 0.741 & 0.309 & 5.752 & 0.016 & $(1.145,3.844)$ & 2.098 \\
\hline Trend of CRP & & 0.744 & 0.260 & 8.229 & 0.004 & $(1.266,3.501)$ & 2.105 \\
\hline Trend of PCT & & 0.266 & 0.311 & 0.733 & 0.392 & $(0.710,2.400)$ & 1.305 \\
\hline
\end{tabular}

\section{Discussions}

Recently years, little research has been reported on the incidence and influence of hypocalcemia in brucellosis. Findings from our study suggested that there was a certain proportion of hypocalcemia in brucellosis patients and around $17.8 \%$ patients were found with it.

Brucellosis is a multi-system disease with diverse clinical manifestations, which may present some atypical symptoms and prompt patients to seek treatment, such as nervous systems (headache, mental symptoms, etc. ${ }^{[15]}$, consistent with previous reports.In this study, headache,anorexia, knee pain and mental symptoms in hypocalcemia group were significantly higher than those in normal corrected calcium group.Among the subjects surveyed, most of the mental symptoms of brucellosis patients are insomnia.According to research, it has been shown that calcium is the brain neuron metabolism indispensable important substances.Sufficient calcium can inhibit the abnormal excitement of brain nerves, making people remain calm.Lack of calcium makes people fidgety and unstable ${ }^{[16]}$.Therefore, it can be speculated that the study object with poor sleep may be lacking of calcium in the body, resulting in emotional ups and downs and inability to sleep peacefully, which further suggests that when brucellosis patients suffer from insomnia, they should pay attention to calcium supplement. 
As with complex clinical complications ${ }^{[17]}$, multiple organ damage can be caused by brucellosis,such as Brucellosis spondylitis.The incidence of meningitis and ion disorder (hyponatremia, hypokalemia and hypocalcemia) in hypocalcemia group was higher than that in normal corrected calcium group, indicating that hypocalcemia affected the occurrence of various systemic diseases, including blood system, nervous system, etc. ${ }^{[18]}$, suggesting that hypocalcemia may be associated with systemic disease in brucella patients.It has been described that CKD can cause nervous system complications through metabolic disorders (such as acidosis, hypocalcemia, hyperphosphatemia) ${ }^{[19]}$. Moreover, associated with the recurrence of hypocalcemia. Hypokalemia was occasionally described in literature ${ }^{[20]}$. Related to syndrome of inappropriate antidiuretic hormone among patients with brucellosis ${ }^{[21]}$, hyponatremia was also occasionally reported.

In our research, the correlation between medication history and brucellosis patients with hypocalcemia was also analyzed.After multivariate Logistic regression analysis , we found that rifampicin antibiotic medication history before the brucellosis confirmed is a risk factor for hypocalcemia, which showed the significant correlation between the application of antibiotic rifampicin class and merger of brucellosis with hypocalcemia, and bolstered the point previously put forward that rifampicin may play a role in the occurrence of hypocalcemia ${ }^{[22]}$.According to literature reports, rifampicin is an enzyme inducer that can increase liver metabolism of 25 -hydroxyvitamin $D$ and reduce circulating level by up to $70 \%{ }^{[23]}$. In people who already have the risk of vitamin $D$ deficiency, rifampicin may cause symptomatic hypocalcemia in the treatment of active tuberculosis ${ }^{[24]}$. Clinicians believe that anti-tuberculosis chimerism uses a standard entrainer, an exhausted vitamin D reserve, and this may be important for a osteomalacia and bone tumor ${ }^{[25]}$.It is speculated that rifampicin may induce hypocalcemia in brucellosis patients by reducing the circulating level of 25 -hydroxyvitamin $D$, which in turn may lead to some bone-related diseases. It is further suggested that clinicians should pay attention to reminding brucellosis patients to bask in the sun and supplement calcium to prevent bone-related diseases.In addition, the history of rifampicin use is a risk factor for hypocalcemia in brucellosis patients, which may further reveal the abuse of antibiotics before diagnosis, which often delays and aggravates the disease. Then secondary complications occur, such as spondylitis, orchitis affecting fertility and life-threatening pleural effusions, which complicates the treatment of brucellosis. From this,we remind the patients to accept medical treatment timely when they feel uncomfortable, obey the doctor's instruction, and standardize the use of medicine.

In conclusion, a retrospective analysis of 572 cases was conducted, in order to better understand clinical features and epidemiological characteristics of brucellosis, and the changes of clinical parameters of brucellosis with hypocalcemia. Meanwhile, we are aimed to provide more scientific evidence on the importance of hypocalcemia in brucellosis. The indicative role of hypocalcemia on rare complications, symptoms and the severity of brucellosis need further evaluation in randomized clinical trials. In addition, primary health care physicians should be alerted when hypocalcemia was checked out in brucellosis patients and the choice of antibiotics should be paid attention to in clinical treatment of brucellosis and remind brucellosis patients to bask in the sun and supplement calcium to prevent some bone-related 
diseases.Finally,we remind the patients to seek medical treatment in time and standardize the use of drugs.

\section{Declarations}

\section{Ethics approval and consent to participate}

The study protocol was approved by the ethics committee of that Hospital of Shenyang, Liaoning province. Due to the retrospective nature of the study, the need for informed consent was waived.

\section{Consent for publication}

Applicable.

\section{Competing interests}

The authors declare that they have no competing interests.

\section{Funding}

Thanks to the Jilin Province Health Technology Innovation Project (20165076) for providing help to our study

\section{Authors' contributions}

ZQ designed and coordinated the study and helped to review the manuscript. ZSW, LJJ ,YHX,WTJ,HJ,ZXY and HFF collected data. ZXH and CQQ analyzed the data and drafted the manuscript. All authors read and approved final version of the manuscript.

\section{Acknowledgments}

We thank a hospital of Shenyang, Liaoning province for their support to our research.

\section{References}

1. Yaman Y, Gözmen S, Özkaya AK, Oymak Y, Apa H, Vergin C, et al. Secondary hemophagocytic lymphohistiocytosis in children with brucellosis: Report of three cases. J Infect Dev Ctries. 2015;9:1172-6.

2. Okur M1, Erbey F, Bektaş MS, Kaya A, Doğan M, Acar MN, Uzun H. Retrospective clinical and laboratory evaluation of children with brucellosis. Pediatr Int. 2012;54:215-8.

3. Luo L, Zhou BT, Wang HL, Dou HT, Li TS.A clinical analysis of six patients with Brucella endocarditis and literature review.Zhonghua Nei Ke Za Zhi. 2017 Oct 1;56(10):734-737.

4. Akbayram S, Dogan M, Akgun C, Peker E, Parlak M, Oner AF.Disseminated intravascular coagulation in a case of brucellosis.Clin Appl Thromb Hemost. 2011 Nov-Dec;17(6):E10-2. 
5. Denk A, Ozden M.A case of brucellosis presenting with acute hepatitis and bicytopenia.Infez Med. 2015 Jun;23(2):178-81.

6. Sankaran RT, Mat tana J, Pollack S, et al.Laboratory abnormalities in patients with bact erial pneumonia .Chest, 1997, $111: 595-600$.

7. Müller, Becker, Kränzlin, et al. Disordered calcium homeostasis of sepsis: association with calcitonin precursors[J]. European Journal of Clinical Investigation, 2000, 30(9):823-831.

8. Malik GM.High serum calcium in human brucellosis: a case-control study.Am J Trop Med Hyg. 1998 Sep;59(3):397-8.

9. AMAL, Al-Hadithi H.. Biochemical study of the effect of typhoid fever and brucellosis infections on some serum salts concentration.Al-Mustansiriyah Journal of Pharmaceutical Sciences (AJPS), [S.I.], v. 1, n. 1, p. 1-6, june 2004.

10. Hagop M.KantarjianM.D.1Mohammad F.SaadM.B., Ch.B.1Elihu H.EsteyM.D.1Rena V.SellinM.D.1 Naguib A.SamaanM.D., Ph.D.1.Hypercalcemia in disseminated candidiasis[J].The American Journal of Medicine,1983,74(4):721-724.

11. Torun A N, Eren M A, Demir M, et al. Recurrent symptomatic hypocalcemia during rifampicin therapy for brucellosis[J]. Wiener Klinische Wochenschrift, 2011, 123(17-18):566-568.

12. David Burgner,Elisabeth Schölvinck,Michael Coren,etc.Chalk and cheese: symptomatic hypocalcaemia during paediatric anti-tuberculous therapy[J].Journal of Infection,2004,49(2):169171.

13. Deon Coley-Grant, Mike Herbert, Michael P Cornes, lan M Barlow , Clare Ford and Rousseau Gama1.The impact of change in albumin assay on reference intervals, prevalence of 'hypoalbuminaemia' and albumin prescriptions.Annals of Clinical Biochemistry 2016, Vol. 53(1) $112-116$

14. Ministry of Health of the People's Republic of China. Health industry standard of the People's Republic of WS269-2007 Brucella disease diagnosis standard [S]. People's Medical Publishing House,2007, 6-10.

15. Nurgul C, RecaiT IE, Asuman I, Derya E, Hulya T, et al. Neurobrucellosis: clinical, diagnostic, therapeutic features and outcome. Unusual clinical presentations in an endemic region. Braz $\mathrm{J}$ Infect Dis. 2011;15(1):52-59.

16. Zhang zheng. Investigation on normal reference values of serum iron and calcium in healthy adults in jinan city and influence of environmental and social behavior factors [D]. Shandong: shandong university,2009.

17. Dean AS, Crump L, Greter H, Hattendorf J, Schelling E, et al. (2012) Clinical Manifestations of Human Brucellosis: A Systematic Review and Meta-Analysis. PLOS Neglected Tropical Diseases 6(12): e1929.

18. Jiang W, Chen J, Li Q, Jiang L, Huang Y, Lan Y, Li Y.Epidemiological characteristics, clinical manifestations and laboratory findings in 850 patients with brucellosis in Heilongjiang Province, China.BMC Infect Dis.2019 May 20;19(1):439. 
19. Hamed SA1.Neurologic conditions and disorders of uremic syndrome of chronic kidney disease: presentations, causes, and treatment strategies. Expert Rev Clin Pharmacol.2019 Jan;12(1):61-90.

20. Torun A N, Eren M A, Demir M, et al. Recurrent symptomatic hypocalcemia during rifampicin therapy for brucellosis[J]. Wiener Klinische Wochenschrift, 2011, 123(17-18):566-568.

21. Dulger A C, Aslan M, Ceylan M R, et al. The Syndrome of Inappropriate Secretion of AntiDiuretic Hormone in Patients With Brucellosis[J]. Journal of Clinical Laboratory Analysis, 2014, 29(5):366369.

22. Ayse Nur Torun, Mehmet Ali Eren, Mehmet Demir, Tevfik Sabuncu.Recurrent symptomatic hypocalcemia during rifampicin therapy for brucellosis.Wien Klin Wochenschr.2011 Sep;123(1718):566-8.

23. Martin J Brodie MD,Alan R Boobis PhD,Carmel J Hillyard PhD,Gamini Abeyasekera BSc,lan Maclntyre MD,B Kevin Park PhD.Effect of isoniazid on vitamin D metabolism and hepatic monooxygenase activity.Clinical Pharmacology and Therapeutics (1981) 30, 363-367.

24. David Burgnera,Elisabeth Schölvinck Michael Coren,Sam Walters.Chalk and cheese: symptomatic hypocalcaemia during paediatric anti-tuberculous therapy.Journal of Infection (2004) 49, 169-171

25. Davies PD, Brown RC, Church HA, Woodhead JS. The effect of anti-tuberculosis chemotherapy on vitamin D and calcium metabolism.Tubercle. 1987 Dec;68(4):261-6. 